\title{
The correlation between the plasma nitric oxide levels and QT/QTc interval in conscious rabbits
}

\author{
Tennur Atabay ${ }^{1}$ and Metehan Uzun ${ }^{2}$ \\ ${ }^{1}$ Department of Physiology, Institute of Health Sciences, Faculty of Veterinary Medicine, University of Kafkas, Kars, Turkey \\ ${ }^{2}$ College of Health Science, Çanakkale Onsekiz Mart University, Çanakkale, Turkey
}

\begin{abstract}
The current study was undertaken to investigate the effects of NOx (plasma concentrations of nitrate plus nitrite which are plasma nitric oxide (NO) metabolites) over QT interval and to determine the level of correlation between them in conscious rabbits.

For this purpose, twenty-one New Zealand rabbits (5-7 months old) were used and randomly assigned into the following three groups: control (CG; $n=7,1 \mathrm{ml}$ isotonic $\mathrm{NaCl}$ solution per ani$\mathrm{mal} /$ day), L-arginine (ARG-G; $n=7$, L-arginine solution $200 \mathrm{mg} / \mathrm{kg} /$ day) and L-NAME (NAME-G; $n=7$, L-NAME solution $100 \mathrm{mg} / \mathrm{kg} /$ day). Injections were performed intraperitoneally at 9:00 a.m. for 9 days. Blood samples were collected $2 \mathrm{~h}$ after the injections on day 1,5 and 9 and the concentration of plasma NOx was determined using a colorimetric method. ECG was also recorded $2 \mathrm{~h}$ after the injection on 1st, 5th and 9th days. The heart rate, QT intervals, corrected QT intervals (QTc) and QT dispersion (QTd), QTc dispersion (QTcd) values were calculated from the ECG recordings.

Statistically significant differences were observed between HR, QT and QTc values in all groups for all days $(p<0.001)$. QTd and QTcd values were found statistically significant different in NAMEG compared to CG and ARG-G $(p<0.001)$. It was also determined that there was a statistically significant correlation between the NOx and HR and QT and QTc in all days.

It is concluded from this study that NO is an important molecule for the electrical activation of heart and has effects on the duration of QT/QTc interval, which should be taken into consideration by the physicians. In addition, application of the L-arginine should be further studied.
\end{abstract}

Key words: Nitric oxide - L-NAME - ECG - QT interval - Rabbit

\section{Introduction}

Nitric oxide (NO), a major messenger molecule in many patho-physiological functions, is synthesized from L-arginine by a family of isoformic enzymes (eNOS, nNOS and iNOS) known as NO synthase (NOS). $\mathrm{L}$-arginine is a substrate for $\mathrm{NO}$ production and $\mathrm{N}^{\omega}$-nitro-L-arginine methyl ester (L-NAME) is a non-selective inhibitor of NOS, which decreases the level of NO production (Moore and Handy 1997). Since NO has very short half life and is highly labile, plasma concentration of nitrate plus nitrite (NOx) is often used as a marker of NO production and NOS enzyme activity.

The QT interval is a reflection of ventricular action potential time in electrocardiograph (ECG) and varies from beat

Correspondence to: Metehan Uzun, Colege of Health Scinece, Çanakkale Onsekiz Mart University, Çanakkale, Turkey

E-mail: metehanuzun@hotmail.com to beat. The prolongation of QT interval may be associated with a polymorphic ventricular tachycardia known as torsade de pointes (TDP). QT dispersion is another factor involved in serious ventricular arrhythmias and indicative of repolarisation heterogeneity across the ventricular muscle (Cubeddu 2003).

In recent years, there is increasing evidence that $\mathrm{NO}$ modulates cardiac physiology and is an important signalling molecule in the cardiovascular system. All of the three isoformic enzymes given above are present in the heart (Paulus et al. 2001). NO pathway has a role in the regulation of heart rate (Sears et al. 1998; Conlon et al. 1996), and it exerts a tonic, direct, positive chronotropic effect on the denervated human heart (Chowdhary et al. 2002).

It was shown that $\mathrm{NO}$ affects the function of $\mathrm{Ca}^{2+}$ and $\mathrm{K}^{+}$ channels (Bai et al. 2005). Although variations in the function of these channels cause changes in QT intervals, there has been no sufficient data how effective in vivo variations of NO synthesis (decreases or increases) for long period of time 
are over QT interval. The current study was undertaken to investigate the effects of NO over QT interval using L-NAME and L-arginine in conscious rabbits and to determine and assess the level of correlation between them.

\section{Materials and Methods}

\section{Animals and groups}

The study involved 21 New Zealand rabbits of both sexes aged between 5 and 7 months old. Rabbits were fed special pelletedrabbit diet ad libitum in cages. Animals were kept at room temperature $\left(22-25^{\circ} \mathrm{C}\right)$ with $12: 12 \mathrm{~h}$ light/dark cycle. The Laboratory Animal Care and Use Committee of Veterinary Faculty of Kafkas University approved all experimental protocols. Animals were divided into one control and two experimental groups.

Control group (CG): this group consisted of seven rabbits of which mean body weight was $2.57 \mathrm{~kg}$. $1 \mathrm{ml}$ isotonic solution of $\mathrm{NaCl}$ was injected intraperitoneally (i.p.) per animal/day during 9 days.

L-arginine group (ARG-G): this group consisted of seven rabbits of which mean body weight was $2.58 \mathrm{~kg}$. L-arginine (FLUKA, catalog No. 11010) was purchased in powder form and L-arginine solution was prepared from this for injections. This solution was injected to the rabbits in this group i.p. at a dose of $200 \mathrm{mg} / \mathrm{kg} /$ day during 9 days. The L-arginine solution was prepared daily $1 \mathrm{~h}$ before each trail.

L-NAME group (NAME-G): the 7 rabbits were used in this group (mean body weight $2.64 \mathrm{~kg}$ ). L-NAME (FLUKA catalog No. 72760) solution obtained in powder form was also injected i.p. at a dose of $100 \mathrm{mg} / \mathrm{kg} /$ day during 9 days.

\section{Collection of blood samples}

Blood samples were collected from auricular vein at 1st, 5 th and 9th day of the trial after $2 \mathrm{~h}$ of the injections. After the collection of blood samples, plasma was obtained and deproteinized immediately and stored at $-20^{\circ} \mathrm{C}$ until the NOx analysis.

\section{NOx determinations}

The concentration of nitrate and nitrite were determined from deproteinized plasma samples according to the method of Miranda et al. (2001) using a spectrophotometric method. The NOx values were calculated from the total nitrite and nitrate levels.

\section{ECG recordings}

ECG procedure was performed as reported by Uzun et al. (2007). Alligator clips were attached to limbs. ECG record- ings were obtained after $2 \mathrm{~h}$ of each injection from each animal at 1st, 5th and 9th day of the trial by direct writing ECG (Logos 8821; Logos Medical Co., Ltd., Tokyo, Japan). ECG was standardised at $1 \mathrm{mV}=20 \mathrm{~mm}$, with chart speed of 50 $\mathrm{mm} / \mathrm{s}$. Leads I, II, III, aVR, aVL and aVF were determined. QT interval was manually calculated from the beginning of $\mathrm{Q}$ wave to the end of T wave. The same leads (II and aVR) were selected for all QT interval measurements. Animals were not given any sedatives or anaesthetics before and during ECG recording.

The QT interval was corrected for heart rate with the use of Carlsson formula as: QTc $=$ QT - $0.175(\mathrm{RR}-300)$ (Carlsson et al. 1993). QT dispersion (QTd) and QTc dispersion (QTcd) were calculated as the difference between the longest and shortest mean QT and QTc interval, respectively.

\section{Statistical analysis}

Treatment means (NOx, HR, QT, QTc, QTd and QTcd) were compared in the groups at 1st, 5th and 9th day statistically by one-way ANOVA (Turkey's $t$-test). The factors effecting (groups and days) the measurements (NOx, HR, QT, QTc, QTd and QTcd) were analysed using the two-way ANOVA using Minitab (version 11.2, 1996). Pearson's correlation test was used to find out the correlation between the NOx and ECG parameters. Data are represented as mean \pm SEM (standard error of mean).

\section{Results}

Three groups of rabbits (CG, ARG-G, NAME-G) were employed in this study and each group consisted of seven animals. All rabbits were healthy throughout the trial. However, data for 18 rabbits were utilized for correlation analysis due to some reasons such as the presence of unreliable ECG results due to over-excited animals and undetection of $\mathrm{NO}$ levels due to haemolysis of the blood samples.

In this study, NOx values were found higher in ARG-G group and lower in NAME-G than in CG for all days on which the blood samples were taken. In addition, it was observed that there were statistically significant differences between ARG-G and CG only in the 9th day, ARG-G and NAME-G, and NAME-G and CG, in 1st, 5th and 9th day $(p<0.001)$. The mean NOx levels in all groups at 1 st, 5 th and 9 th days can be seen in Table 1 .

The HR, QT, QTc, QTd and QTcd values were calculated from the ECG recordings of the rabbits used in the present investigation. The representative ECGs with lead II of one rabbit for each group are shown in Fig 1. Statistically significant differences were seen amongst values in all groups $(p=0.001$, Figs. $2-6)$. Heart rates were increased in ARG-G and bradycardia was observed 
in NAME-G. QT and QTc values were shortened in ARG-G and prolonged in NAME-G in comparison with CG. The relations of analysed parameters were found to be statistically significant group-dependent manner $(p<$ 0.001), however, not time-dependent.

In this study, the values of all groups were used together in order to determine correlation between NO and HR, QT and QTc. It was also determined that there was a statistically significant correlation amongst the NOx and HR values $(r=$ $0.72, p \leq 0.001$ for day $1 ; r=0.78, p<0.001$ for day 5 and $r=$ $0.92, p<0.001$ for day 9 ), QT $(r=-0.59, p<0.01$ for day 1 ; $r=-0.85, p<0.001$ for day 5 and $r=-0.88, p<0.001$ for day 9) and QTc $(r=-0.59, p<0.01$ for day $1 ; r=-0.85, p<$ 0.001 for day 5 and $r=-0.88, p<0.001$ for day 9) for all days (Figs. 7-9).

Table 1. The plasma NO concentration in experimental groups at $1 \mathrm{st}$, 5th and 9th days of trial. $1 \mathrm{ml}$ isotonic solution of $\mathrm{NaCl}$, $200 \mathrm{mg} / \mathrm{kg} /$ day of L-arginine solution and $100 \mathrm{mg} / \mathrm{kg} /$ day of LNAME solution were i.p. injected per animal during 9 days in control (CG), L-arginine (ARG-G) and L-NAME (NAME-G) groups, respectively

\begin{tabular}{|l|c|c|c|}
\hline \multirow{2}{*}{$\begin{array}{l}\text { Groups } \\
(n=7)\end{array}$} & \multicolumn{3}{|c|}{$\mathrm{NO}(\mu \mathrm{mol} / \mathrm{l})$} \\
\cline { 2 - 4 } & 1st day & 5th day & 9th day \\
\hline CG & $36.48 \pm 3.9$ & $36.98 \pm 1.9$ & $36.04 \pm 2.9$ \\
ARG-G & $43.30 \pm 8.1$ & $42.71 \pm 4.1$ & $45.30 \pm 5.4^{* * *}$ \\
NAME-G & $25.77 \pm 5.0^{* * *}$ & $22.28 \pm 7.5^{* * *}$ & $20.30 \pm 3.8^{* * *}$ \\
\hline
\end{tabular}

Values are different from each other with different superscript in the same column, ${ }^{* *} p<0.001$.
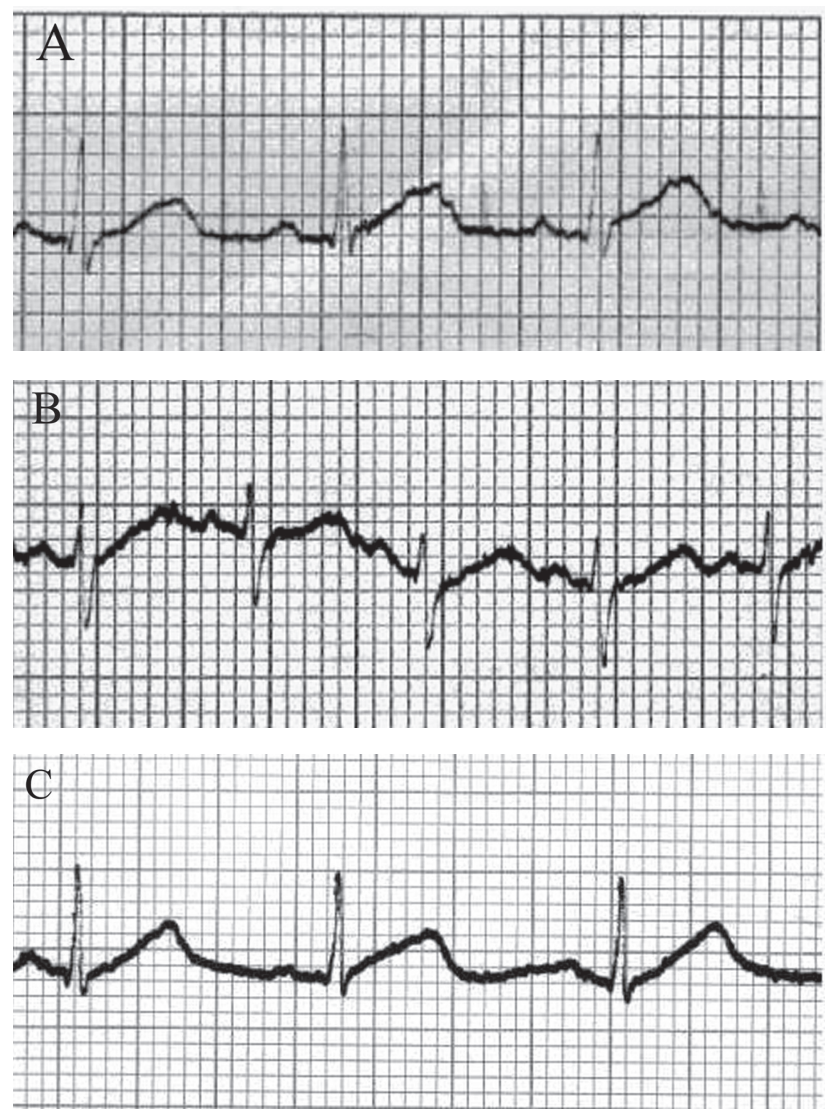

Figure 1. Representative ECG patterns in CG (A), increased heart rate in ARG-G (B), decreased heart rate and prolongation of the QT interval in NAME-G (C) from Lead II (ECG was standardized at $1 \mathrm{mV}=20 \mathrm{~mm}$, with chart speed of $50 \mathrm{~mm} / \mathrm{s}$ ).

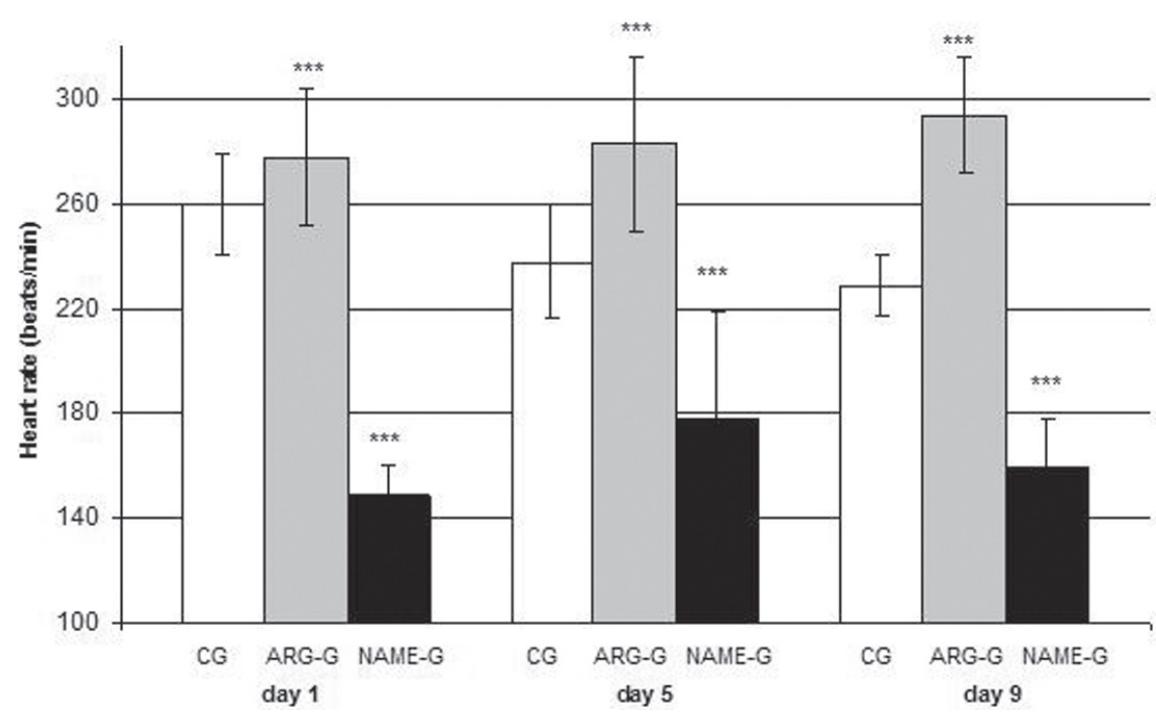

Figure 2. The mean heart rate values in CG, ARG-G and NAME-G groups at 1st, 5th and 9th day. Values are different from each other with different superscript $\left({ }^{* *} p<0.001\right)$. 


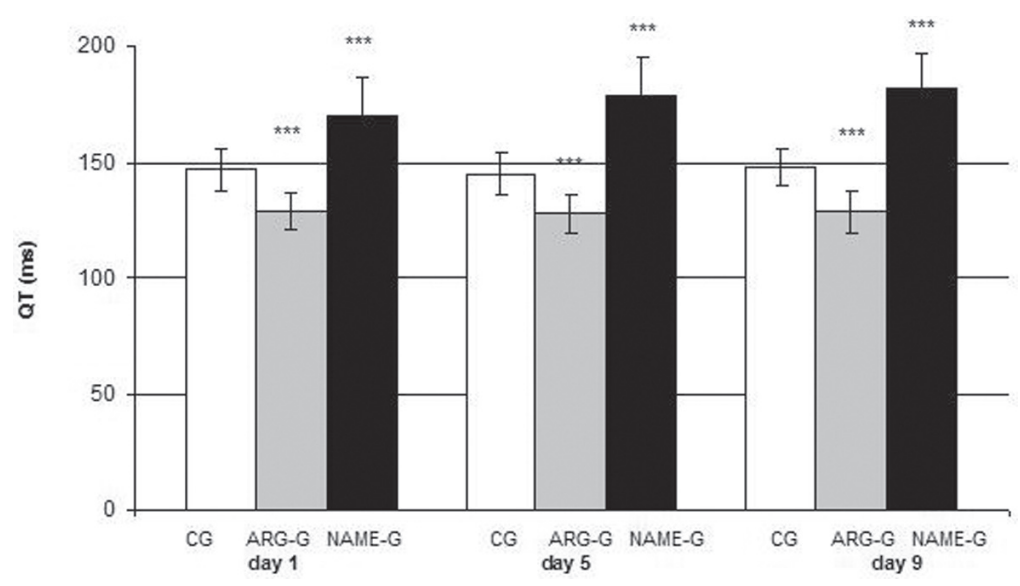

Figure 3. The mean QT values in CG, ARG-G and NAME-G groups at 1st, 5th and 9th day. Values are different from each other with different superscript $\left({ }^{\star * *} p<0.001\right)$.

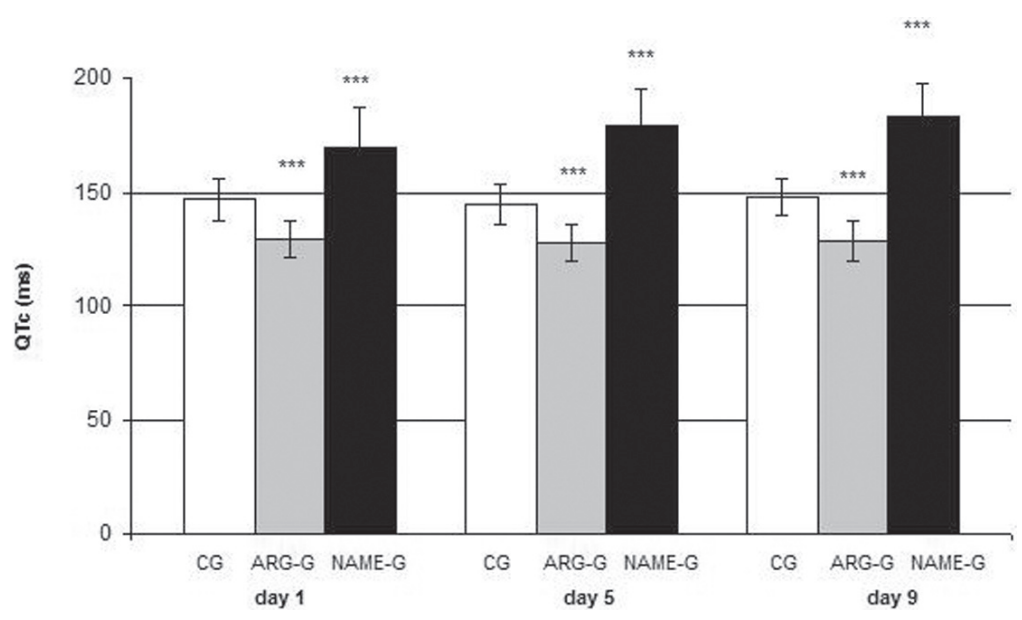

Figure 4. The mean QTc values in CG, ARG-G and NAME-G groups at 1st, 5th and 9th day. Values are different from each other with different superscript $\left({ }^{* *} p<0.001\right)$.

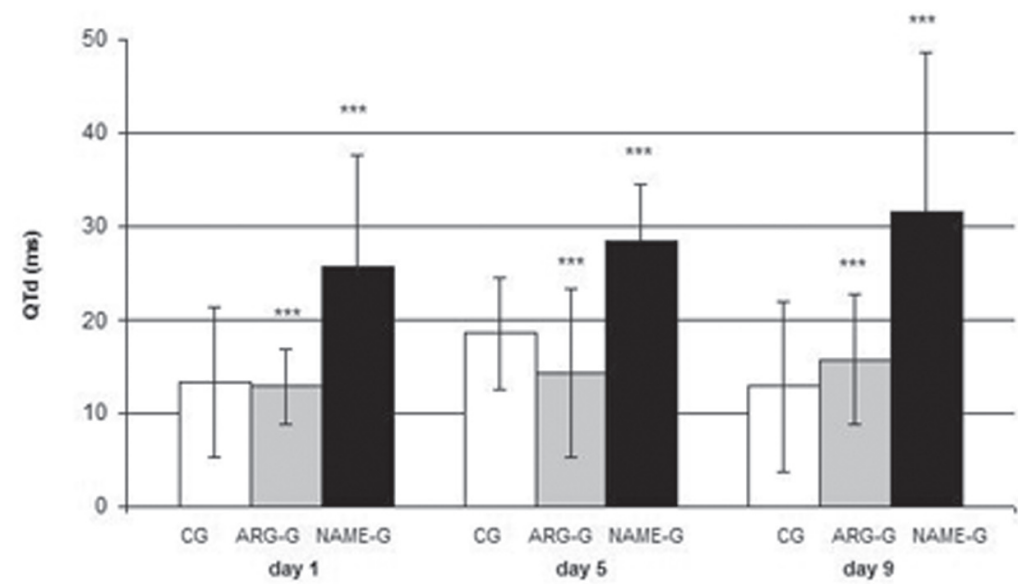

Figure 5. The mean QTd values in CG, ARG-G and NAME-G groups at 1st, 5th and 9th day. Values are different from each other with different superscript $\left({ }^{\star * *} p<0.001\right)$. 


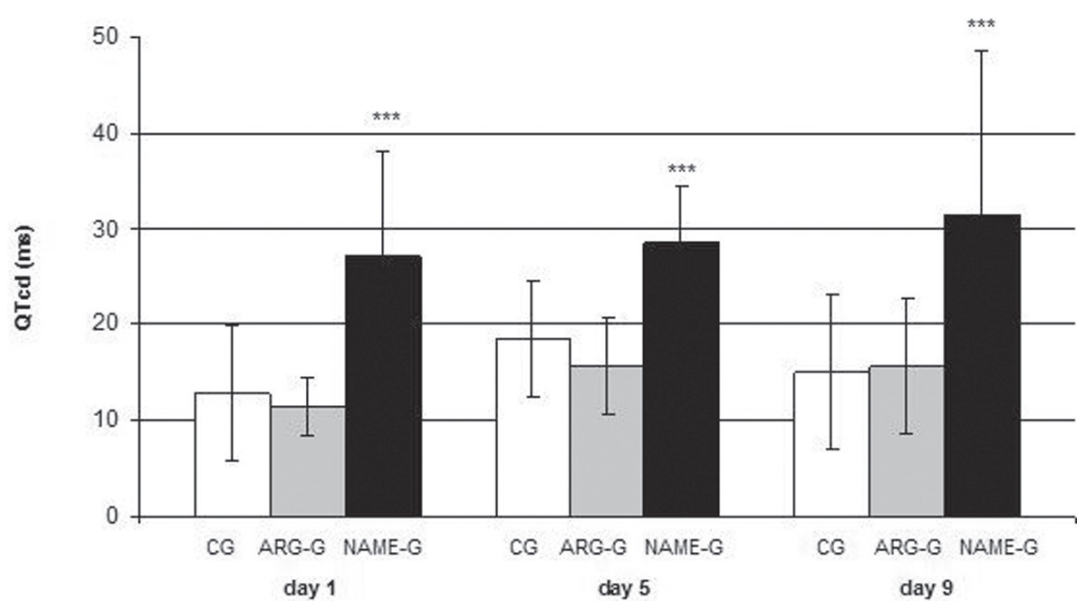

Figure 6. The mean QTcd values in CG, ARG-G and NAME-G groups at 1st, 5th and 9th day. Values are different from each other with different superscript $\left.{ }^{* * *} p<0.001\right)$.

A

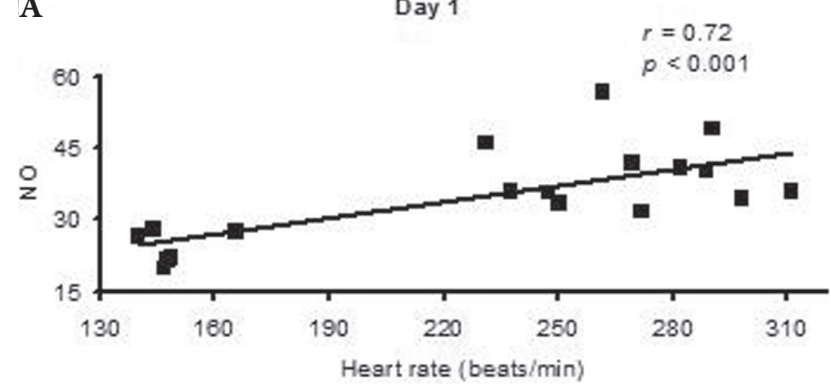

B
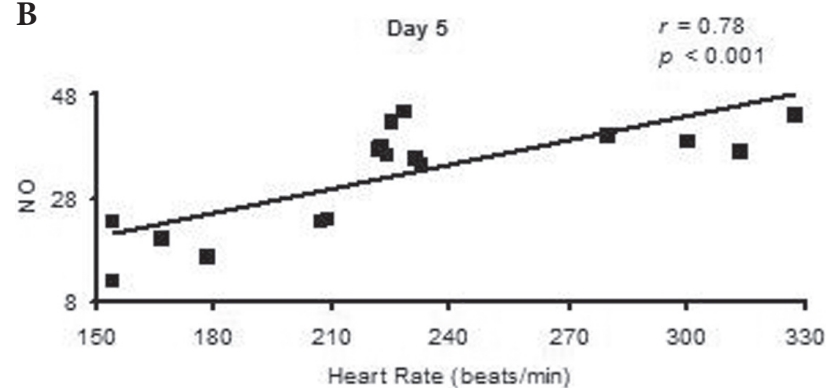

C

Day 9

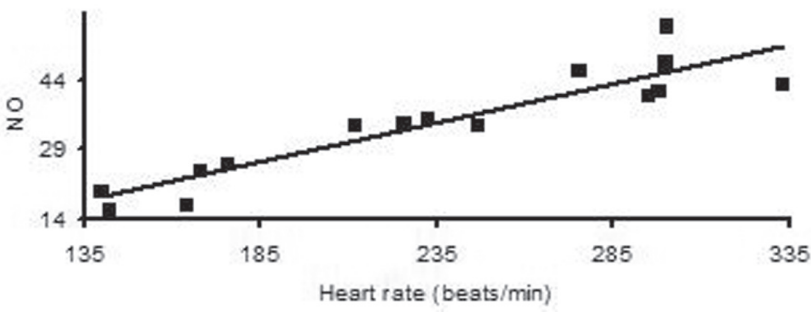

Figure 7. Relationship between NO and heart rate on 1st (A), 5th (B) and 9th (C) day of trial.

\section{Discussion}

To our knowledge, this is the first in vivo study to investigate correlation between blood NOx levels and QT/QTc values in healthy and conscious rabbits.

The current study aimed at increasing NO synthesis by administration of L-arginine as $\mathrm{NO}$ donor and decreasing NO synthesis with the administration of L-NAME to determine the effects of NO on ECG parameters in rabbits. NOx levels were detected by collecting blood samples after the 1st, 5 th and 9th days of the injections. The results showed that NO levels were $42.71-45.30 \mu \mathrm{mol} / \mathrm{l}$ in ARG-G that is higher than the CG. In addition, NO levels were 20.30-25.77 $\mu \mathrm{mol} / 1$ in NAME-G that is lower than the CG and the differences were statistically significant (Table $1, p<0.001$ ). It was also observed that differences were also statistically significant between ARG-G and NAME-G for all days, which suggest that arginine functioned as NO donor and L-NAME functioned as NO synthesis inhibitor in rabbits in the present study. Although a statistically apparent increase in NO levels was not seen in ARG-G (except for 9th day) as compared to the CG, which differed statistically from NAME-G for all days examined. Therefore, variations at blood NO values seemed to be at the sufficient levels for assessment of the effects of NO over ECG. Statistical results revealed that changes in NOx and ECG parameters were significantly associated with ARG and L-NAME application $(p<0.001)$, but not days.

Recent in vivo and in vitro studies have demonstrated that NO increases the heart rate and have a positive inotropic and chronotropic effects on heart (Hogan et al. 1999; Chowdhary et al. 2002). In this investigation, heart rate in CG was within the range of $238-260$ beats/min whereas it decreased down to $149-179$ beats/min in NAME-G and risen 
A

Day 1

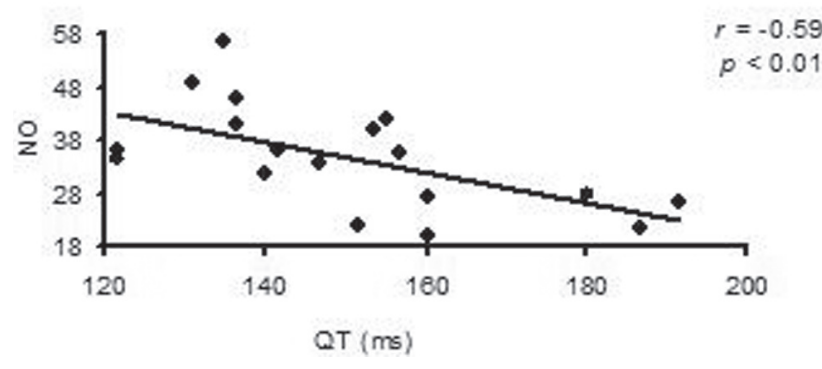

B

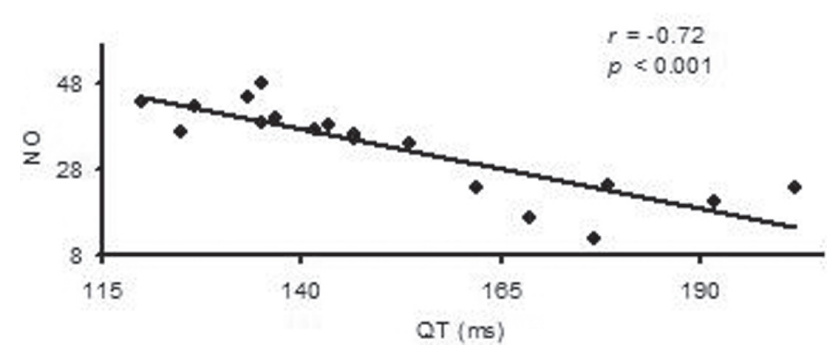

C

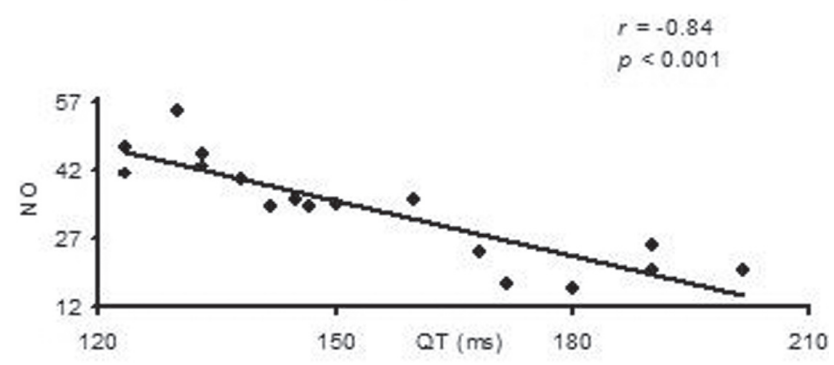

Figure 8. Relationship between NO and QT on 1st (A), 5th (B) and 9th (C) day of trial.

up to 278-311 beats/min in ARG-G. These findings were in agreement with current literature data. Arginine is regarded as a donor stimulating $\mathrm{NO}$ synthesis. NO donors function by activating action potential in pace maker cells through cyclic guanozine monophosphate (cGMP) (Musialek et al. 1997). On the other hand, it was reported that chronic administration of L-NAME in rats decreased the heart rate significantly (Scrogin et al. 1998). This is due to effect of $\mathrm{NO}$ on the regulation of parasymphatic tonus in the heart. It was reported that acute inhibition of NO synthesis causes bradycardia (Okuyama et al. 2007).

The findings of the current study showed that QT/QTc interval prolonged significantly in NAME-G whereas this interval shortened in ARG-G as compared to the NAME-G. QT interval prolongation predisposes the development of cardiac arrhythmias such as TDP (Heist and Ruskin 2005).

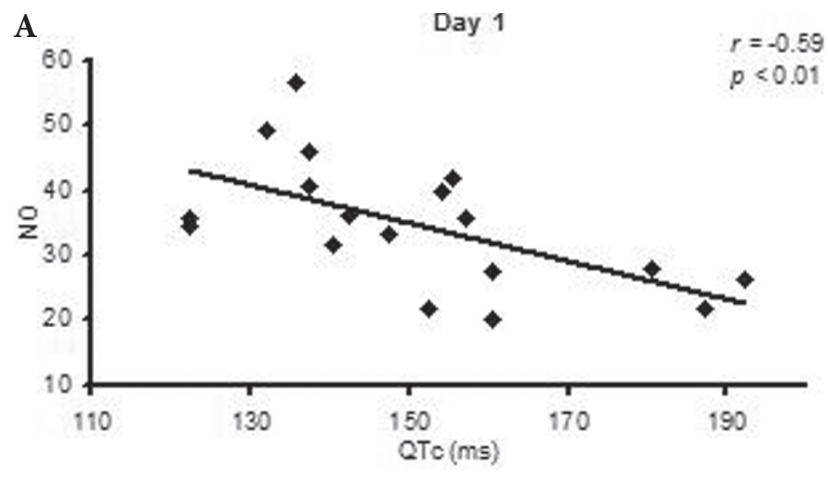

B
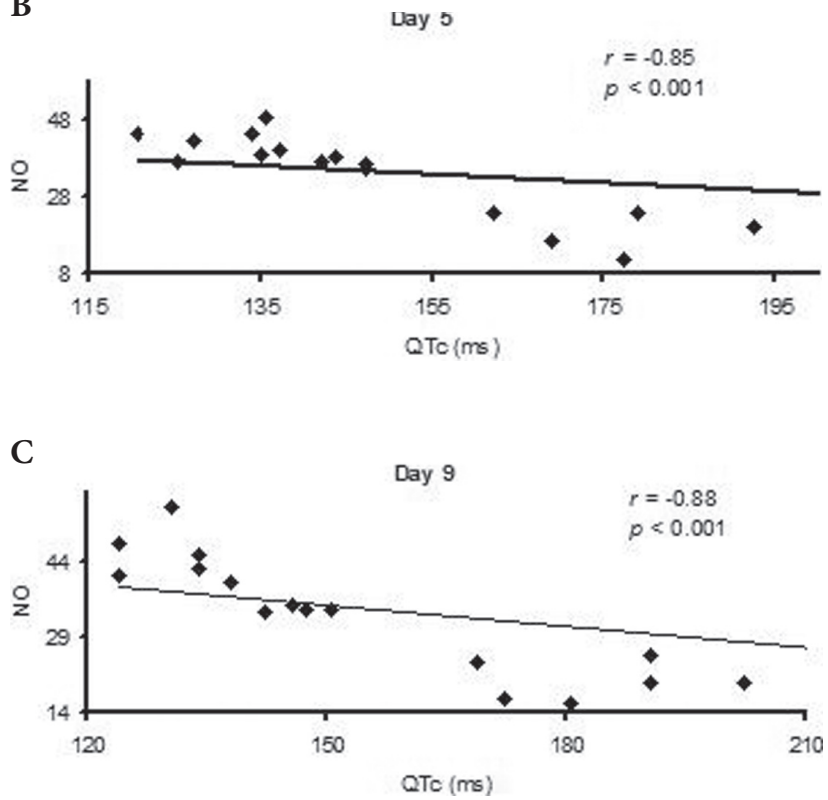

Figure 9. Relationship between NO and QTc on 1st (A), 5th (B) and 9 th $(\mathrm{C})$ day of trial.

According to those results it may be stated that L-NAME, an NOS inhibitor, may increase the life-threatening cardiac arrhythmias by prolonging the QT/QTc interval. This can be achieved by different ways. One of them can be regarded as the effect of $\mathrm{NO}$ on maintaining the amount of $\mathrm{Ca}^{2+}$ entry in cardiomyocytes. Intracellular $\mathrm{Ca}^{2+}$ concentration is tightly regulated by $\mathrm{Ca}^{2+}$ channel. Prolongation of the duration of action potential in heart is seen as the prolongation of the QT interval in ECG. Increase in $\mathrm{Ca}^{2+}$ concentration of heart cells is one of the reasons causing prolongation of this period and it may trigger ventricular arrhythmias (Roden et al. 1996). On the other hand, early after depolarization is known as the voltage fluctuations during action potential repolarization on cell membrane and it is stated that these fluctuations cause prolongation of QT interval causing TDP (Roden et al. 1996). It was demonstrated that NO has an important role 
on the physiologic modulation of $\mathrm{Ca}^{2+}$ cycles in myocyte cells (Khan et al. 2003). It was shown that both NOS1 (localized in sarcoplasmic reticulum) and NOS3 (localized in T-tubule) are expressed in cardiac myocytes (Barouch et al. 2002; Khan et al. 2003). In addition, Bai et al. (2003) demonstrated that L-type $\mathrm{Ca}^{2+}$ channels can be suppressed by NO via cGMP. Furthermore, Bai et al. (2005) reached the conclusion that regulation of slowly-inactivating $\mathrm{K}$ currents $\left(I_{\mathrm{Ks}}\right)$ by $\mathrm{Ca}^{2+}$ is important for $\mathrm{NO}$-dependent $\mathrm{Ca}^{2+}$ cycling system. The reason for the prolongation of QT interval observed in NAME-G in this study may be due to a decrease in NO synthesis in heart and termination of the suppressing effect of NO over L-type $\mathrm{Ca}^{2+}$ current $\left(I_{\mathrm{Ca}, \mathrm{L}}\right)$. It may be concluded that suppressing effect of NOS may have a potential inducing the TDP type of ventricular tachycardia. In addition, the following two reports may support our conclusion. Wang et al. (2008) reported that NOS3 inhibits the $\beta$-adrenergic response by reducing $I_{\mathrm{Ca}, \mathrm{L}}$ and by that it protects against arrhythmia which may associate with a heart failure. The expression CAPON protein in heart was reported by Chang et al (2008) and this protein contribute with NOS1 to accelerate cardiac repolarization by inhibition of L-type $\mathrm{Ca}^{2+}$ channel.

Another mechanism that NO can show its effect on QT/ QTc duration may be through $\mathrm{K}^{+}$channels. $\mathrm{K}^{+}$channels present in the heart controls resting membrane potential, heart rate and duration of action potential. Neurotransmitters, drugs and toxins that effect heart activities target the $\mathrm{K}^{+}$channels. The chemicals affecting these channels cause prolongation of the QT intervals in ECG by extending the action potential period. Bai et al. (2004) determined that NO shows its effect on $I_{\mathrm{Ks}}$ through $S$-nitrolisation of channel proteins. For instance, the effect of increased $I_{\mathrm{Ks}}$ in guinea pig cardiomyocytes by the administration of ginsenoside $\mathrm{Re}$ was almost inhibited by $S$-methylthiourea, an NOS inhibitor. On the other hand, administration of sodium nitroprusside, a NO donor, caused apparent rise in $I_{\mathrm{Ks}}$ effects. In addition, it was reported that NOS inhibitors suppressed the effect of $I_{\mathrm{Ks}}$ activated by $\mathrm{Ca}^{2+}$ and the increase in $I_{\mathrm{Ks}}$ kinetics activated by $\mathrm{Ca}^{2+}$ is formed in a similar manner by $\mathrm{NO}$ donors (Bai et al. 2005). The presence of NOS1 and NOS3 in cardiomyocyte cells is known (Barouch et al. 2002; Khan et al. 2003). It is considered that the L-NAME injected to the rabbit in the current study inhibited NO synthesis by decreasing the activities of those enzymes and caused the prolongation of QT/QTc duration by suppressing the effect of $I_{\mathrm{Ks}} v i a$ this pathway. On the contrary, the reason for the shortened action potential in the group received L-arginine that stimulated NO synthesis may also be implicated as positive effect of $\mathrm{NO}$ over $I_{\mathrm{Ks}}$.

Although we observed a statistically significant QT/QTc prolongation in L-NAME injected rabbits, no TDP type ventricular arrhythmia was determined in any of the rabbits in this study. This is an expected result since all the QTc prolongation may not cause these types of arrhythmias but may predispose for them in other risk factors such as female sex, structural heart disease, hypokalemia, family history of congenital long QT syndrome (Gupta et al. 2007). In addition, this study was an experimental investigation on limited numbers of rabbits. The studies conducted on the drugs causing QTc prolongation which cause TDP type ventricular arrhythmia are found on numerous human objects (sometimes 1000 and more) and these types of arrhythmias are observed in very few of them. However, these arrhythmias are important due to their lethality. Therefore, hypothesis put forward out of this investigation should be tested on more experimental animals in the future studies. The animal groups used in this study consisted of the animal groups used in this study consisted of both male and female rabbits. However, the female gender has been associated with longer QT interval. It seems that women may have a similar uncorrected QT interval compared to men but with a slightly faster heart rate, explaining their longer QTc interval (Drici 2001). Therefore, the future study utilizing more animals should be useful with the consideration of genders.

Observation of the apparent prolongation of QT/QTc durations in healthy conscious rabbits of which NO synthesis was decreased by the L-NAME administration in the current study may suggest that NO may be one of the key molecules in arrhythmias if the diseases, bacterial agents, chemicals or drugs suppressing NOS activities have relations with arrhythmias. These findings should also be taken into consideration by the physicians. In addition, application of L-arginine should be further studied.

Acknowledgements. This work was gratefully supported by The Scientific and Technological Research Council of Turkey (project TOVAG 105 O 638) and partly summarized from the PhD thesis of first author.

\section{References}

Bai C.-X., Sunami A., Namiki T., Sawanobori T., Furukawa T. (2003): Electrophysiological effects of ginseng and ginsenoside Re in guinea-pig ventriculer myocytes. Eur. J. Pharmacol. 476, 35-44

Bai C.-X., Takahashi K., Masumiya H., Sawanobori T., Furukawa T. (2004): Nitric oxide-dependent modulation of the L-type $\mathrm{Ca}^{2+}$ current by ginsenoside $\mathrm{Re}$, an ingredient of Panax ginseng, in guinea-pig cardiomyocytes. Br. J. Pharmacol. 142, 567-575

Bai C.-X., Namekata I., Kurokawa J., Tanaka H., Shigenobu K., Frukawa T. (2005): Role of nitric oxide in $\mathrm{Ca}^{2+}$ sensitivity of the slowly activating delayed rectifier $\mathrm{K}^{+}$current in Cardiac Myocytes. Circ. Res. 96, 64-72

Barouch L. A., Harrison R. W., Skaf M. W., Roses G. O., Cappola T. P., Kobeissi Z. A., Hobai I. A., Lemmon C. A., Burnett A. L., O’Rourke B., Rodriguez E. R., Huang P. L., 
Lima J. A., Berkoitz D. E., Hare J. M. (2002): Nitric oxid regulates the heart by spatial confinement of nitric oxide synthas isoforms. Nature 416, 337-339

Carlsson L., Abrahamsson C., Andersson B., Duker G., SchillerLinhardt G. (1993): Proarrythmic effects of the class III agent almokalant: Importance of infusion rate, QT dispersion, and early afterdepolarisations. Cardiovasc. Res. 27, 2186-21933

Chang K. C., Barth A. S., Sasano T., Kizana E., Kashiwakura Y., Zhang Y., Foster D. B., Marbán E. (2008). CAPON modulates cardiac repolarization via neuronal nitric oxide synthase signaling in the heart. Proc. Natl. Acad. Sci. U.S.A. 105, 4477-4482

Chowdhary S., Harrington D., Bonser R. S., Coote J. H., Townend J. N. (2002): Chronotropic effects of nitric oxide in the denervated human heart. J. Physiol. 541, 645-651

Conlon K. Y., Collins T., Kidd C. (1996): Modulation of vagal actions on heart rate produced by inhibition of nitric oxide synthase in the anaesthetized ferret. Exp. Physiol. 81, 547-550

Cubeddu L. X. (2003): QT prolongation and fatal arrhythmias: a review of clinical implications and effects of drugs. Am. J. Ther. 10, 452-457

Drici M. D. (2001): Influence of gender on drug-acquired long QT syndrome. Eur. Heart J. Suppl. 3, K41-47

Gupta A., Lawrence A. T., Krishnan K., Kavinsky C. J., Trohman R. G. (2007): Current concepts in the mechanisms and management of drug-induced QT prolongation and torsade de pointes. Am. Heart J. 153, 891-899

Heist E. K., Ruskin J. N. (2005): Drug-induced proarrhythmia and use of QTc-prolonging agents: Clues for clinicians. Heart Rhythm 2, 1-8

Hogan N., Casadei B., Paterson D. (1999): Nitric oxide donors can increase heart rate independent of automatic activation. J. Appl. Physiol. 87, 97-103

Khan S. A., Skaf M. W., Harrison R. W., Lee K., Minhas K. M., Kumar A., Fradley M., Shoukas A. A., Berkowitz D. E., Hare J. M. (2003): Nitric oxide regulation of myocardial contractility and calcium cycling: independent impact of neuronal and endothelial nitric oxide synthases. Circ. Res. 92, 1322-1329
Miranda K. M., Espey M. G., Wink D. A. (2001): A rapid, simple spectrophotometric method for simultaneous detection of nitrate and nitrite. Nitric Oxide 5, 67-71

Moore P. K., Handy R. L. C. (1997): Selective inhibitors of neuronal nitric oxide synthase - is no NOS really good NOS for the nervous system? Trends Pharmacol. Sci. 18, 204-211

Musialek P., Lei M., Brown H. F. (1997): Nitric oxide can increase heart rate by stimulating the hyperpolarization-activating inward current, I(f). Circ. Res. 81, 60-68

Okuyama C. E., Mendes G. D., Faro R., Rezende V. M., Lagos R. M., Astigarraga R. E., Antunes E., De Nucci G. (2007): Pharmacokinetics and pharmacodynamics of a nitric oxide-releasing derivative of enalapril in male beagles. Clin. Exp. Pharmacol. Physiol. 34, 290-295

Paulus W. J., Frantz S., Kelly R. A. (2001): Nitric oxide and cardiac contractility in human heart failure: time for reappraisal. Circulation 104, 2260-2262

Roden D. M., Lazzara R., Rosen M., Schwartz P. J., Towbin J., Vincent G. M. (1996): Multiple mechanisms in the long-QT syndrome: current knowledge gaps, and future directions. Circulation 94, 1996-2012

Sears C. E., Choate J. K., Paterson D. J. (1998): Inhibition of nitric oxide synthase slows heart rate recovery from cholinergic activation. J. Appl. Physiol. 84, 1596-1603

Scrogin K. E., Hatton D. C., Chi Y., Luft F. C. (1998): Chronic nitric oxide inhibition with L-NAME: effects on autonomic control of the cardiovascular system. Am. J. Physiol., Regul. Integr. Comp. Physiol. 274, R367-374

Uzun M., Yapar K., Uzlu E., Citil M., Erdogan H. M. (2007): QT interval prolongation and decreased heart rates after intravenous bolus oxytocin injection in male and female conscious rabbits. Gen. Physiol. Biophys. 26, 168-172

Wang H., Kohr M. J., Wheeler G., Ziolo M. T. (2008): Endothelial nitric oxide synthase decreases $\beta$-adrenergic responsiveness via inhibition of the L-type $\mathrm{Ca}^{2+}$ current. Am. J. Physiol., Heart Circ. Physiol. 294, H1473-1480

Received: May 30, 2008

Final version accepted: October 7, 2008 